\title{
Preemptive analgesia after lumbar spine surgery by pregabalin and celecoxib: a prospective study
}

This article was published in the following Dove Press journal:

Drug Design, Development and Therapy

\author{
Nguyen Trung Kien' \\ Phillip Geiger ${ }^{2}$ \\ Hoang Van Chuong' \\ Nguyen Manh Cuong' \\ Ngo Van Dinh' \\ Dinh Cong Pho ${ }^{3}$ \\ $\mathrm{Vu}$ The Anh' \\ Nguyen Truong Giang ${ }^{4}$ \\ 'Department of Anesthesia and Pain \\ Medicine, Military Hospital 103, Vietnam \\ Military Medical University, Hanoi, \\ Vietnam; ${ }^{2}$ Department of Anesthesiology, \\ Perioperative, and Pain Medicine, Naval \\ Medical Center Portsmouth, Portsmouth, \\ VA, USA; ${ }^{3}$ Faculty of Medicine, Vietnam \\ Military Medical University, Hanoi, \\ Vietnam; ${ }^{4}$ Department of Cardiothoracic \\ Surgery, Military Hospital 103, Vietnam \\ Military Medical University, Hanoi, \\ Vietnam
}

Objective: To evaluate the preemptive analgesic effect of combination pregabalin with celecoxib for lumbar spine surgery.

Methods: A prospective, randomized study was conducted among 60 lumbar spine surgery patients and divided into two groups. Postoperative pain relief was achieved with intravenous patient-controlled analgesia with morphine. The preemptive analgesia group received oral pregabalin $(150 \mathrm{mg})$ and celecoxib $(200 \mathrm{mg}) 2 \mathrm{hrs}$ before surgery, and the control group received a placebo. Pain was assessed by visual analogue scale (VAS). Side effects and morphine consumption were monitored until 48 hrs after surgery.

Results: VAS score at rest and during movement was statistically significantly lower in the preemptive analgesia group at most time points $(p<0.05)$. Morphine consumption was significantly lower in the preemptive analgesia group compared with control group in the 24 first hours $(29.03 \pm 4.38 \mathrm{mg}$ vs $24.43 \pm 4.94)$ and $48 \mathrm{hrs}(52.23 \pm 9.57 \mathrm{mg}$ vs $44.20 \pm 10.21$ $\mathrm{mg}), p<0.05$. Hemodynamics, respiratory rate, and $\mathrm{SpO}_{2}$ were similar for both groups. The sedation score was only statistically significant at $\mathrm{H} 8$ time point. The incidence of nausea/ vomiting in the preemptive group did not statistically differ from the control group.

Conclusion: Preoperative administration of pregabalin combined with celecoxib had a good preemptive analgesia effect and reduced intravenous morphine consumption after lumbar spine surgery. Side effects were mild and transient.

Keywords: preemptive analgesia, pregabalin, celecoxib, lumbar spine surgery

\section{Introduction}

Postoperative pain management is an ongoing challenge and involves risk of side effects and complications during recovery, especially for major surgeries or patients with co-existing diseases. A survey by Apfelbaum, J.L showed that $80 \%$ patients $(n=250)$ experienced postoperative pain and that $86 \%$ of them had moderate, severe, or extreme pain. ${ }^{1}$ Lumbar spine fusion surgeries result in significant pain after surgery due to a long skin incision, trauma from tissue retractors used to expand the surgical space, surgical implants, and long operative time. After spine surgery from 6 weeks to 6 months, Coronado et al, found that $12.9 \%$ of the patients continued to experience persistent back pain, $24.2 \%$ had pain that interfered with sleep or other activities, and $46.8 \%$ suffered from disability. This study also showed that good perioperative pain control reduces the rate of chronic pain after spine surgery. $^{2}$

Multimodal analgesia with various pharmacologic agents was effective in providing adequate pain management, as well as improving functional outcome, early ambulation, early discharge, and reducing the incidence of chronic pain. ${ }^{3,4}$ It is a
Correspondence: Nguyen Truong Giang Department of Cardiothoracic Surgery, Military Hospital 103, Vietnam Military Medical University, 26I Phung Hung road, Ha Dong District, Hanoi I00000, Vietnam Tel +84983021818

Email truonggiang.dr@gmail.com 
key contributor to enhance recovery pathways. ${ }^{5}$ Reducing postoperative pain improves the quality of life and satisfaction of patients. ${ }^{6}$

Preemptive analgesia with pregabalin $150-300 \mathrm{mg}$ orally perioperatively has been shown to reduce pain intensity and narcotic consumption after spinal surgery. ${ }^{7}$ The preemptive effect of combination pregabalin and celecoxib in spine fusion surgeries still needs further study. Our study aimed to evaluate the preemptive analgesic effect of combination pregabalin with celecoxib for lumbar spine surgery.

\section{Methods}

\section{Materials and methods}

This study was a prospective, randomized study to evaluate the efficacy of a preemptive analgesia for postoperative pain management.

Consolidated Standards of Reporting Trials (CONSORT) guidelines for reporting randomized trials (http://www.consort-statement.org/) were provided as a CONSORT flow diagram (Figure 1).

The study was carried out on elective spine fusion surgery patients in American Society of Anesthesiologists (ASA) physical status I-III from March to September 2017. The procedure and analgesic methods were explained to all patients, and informed consent was obtained before surgery and enrollment in this study. Exclusion criteria were: 1) history of lumbar spine surgery, 2) recent local anesthesia, 3) prior use of pregabalin or celecoxib, 4) allergy or other contraindication to pregabalin or celecoxib, 5) a comorbid alcohol, opioid, or other substance abuse disorder, 6) failure to adhere to the postoperative follow-up protocol, and 7) major surgical complications.

Patients enrolled study before surgery and were randomly divided into two groups by computer-based method. The preemptive analgesia group received 150 $\mathrm{mg}$ of pregabalin and $200 \mathrm{mg}$ of celecoxib orally $2 \mathrm{hrs}$ before induction with $30 \mathrm{~mL}$ of water, while the control group received placebo with the same amount of water.

All patients had an intravenous line inserted in the operating theatre and their vital signs monitored closely with a Nihon Kohden monitor. Induction of general anesthesia was achieved with propofol $2 \mathrm{mg} / \mathrm{kg}$, rocuronium $1 \mathrm{mg} / \mathrm{kg}$, and fentanyl $2 \mathrm{mcg} / \mathrm{kg}$. Anesthesia was maintained with sevoflurane $2-4 \%$ and fentanyl

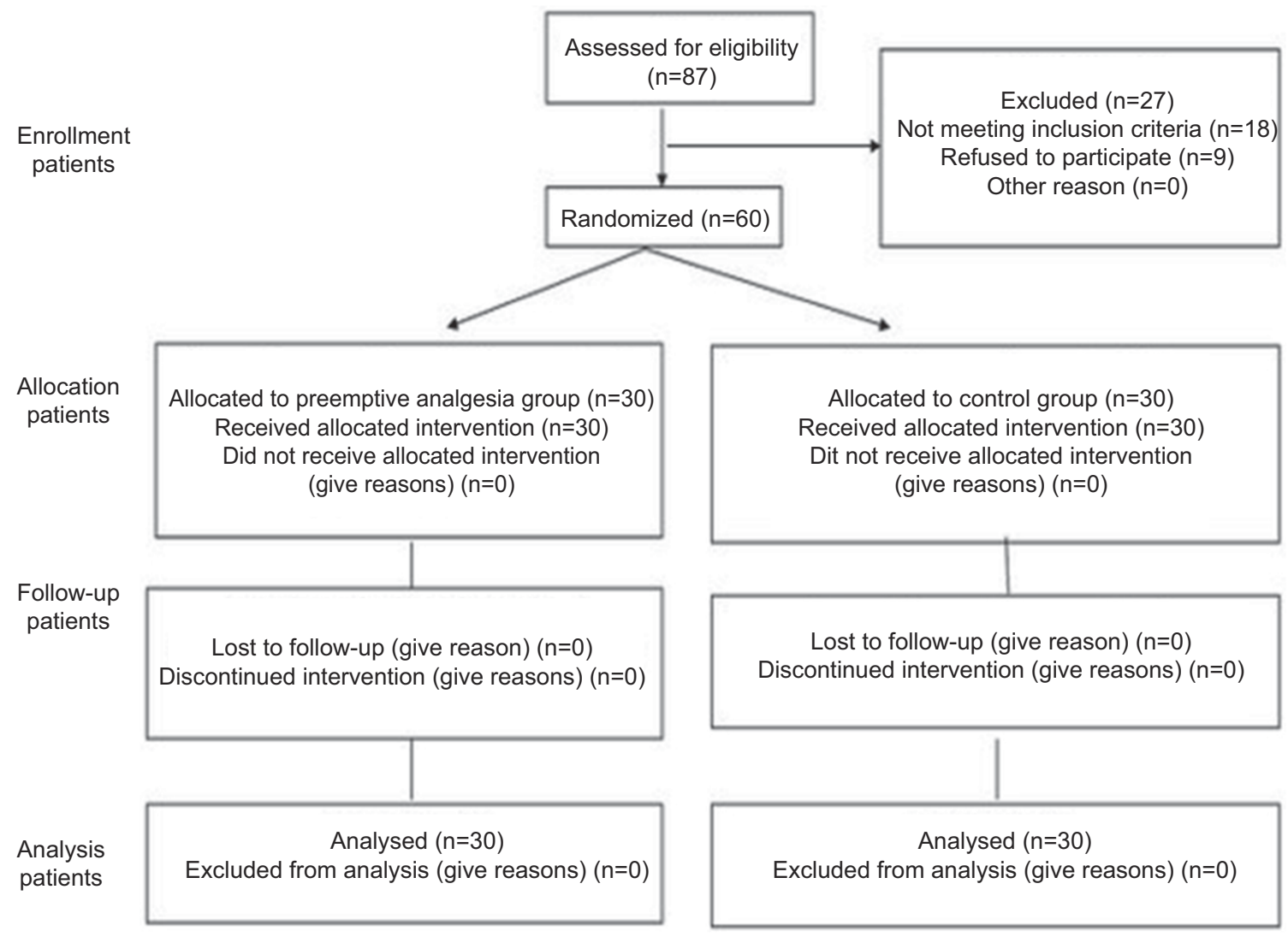

Figure I CONSORT study participant flow diagram. 
$2 \mathrm{mcg} / \mathrm{kg} / \mathrm{hr}$. Surgery was performed in the prone position. Anesthetic agents were stopped at the end of surgery, and patients were returned to the supine position before reversing rocuronium with $0.03 \mathrm{mg} / \mathrm{kg}$ neostigmine and 0.02 $\mathrm{mg} / \mathrm{kg}$ atropine.

All patients were extubated in the operating room before transferring to post-anesthesia care unit (PACU) with standard monitoring. In the PACU, postoperative pain was assessed by a visual analogue scale (VAS) of 0-10 (0: no pain, 1-3: mild pain, 4-6: moderate pain, 7-9: severe pain, 10: miserable pain). When VAS score over 4, patients were given morphine $2 \mathrm{mg}$ every 3 mins until VAS score was lower than 4. At this time, intravenous patient-controlled analgesia (PCA) program was started with bolus dose $1 \mathrm{mg}$, lockout interval $10 \mathrm{mins}$, and a cumulative dose limited to $8 \mathrm{mg}$ per $4 \mathrm{hrs}$. Rescue analgesia with fentanyl $0.5 \mathrm{mcg} / \mathrm{kg}$ was provided if a patient had three consecutive successful PCA attempts, but VAS score was still over 4.

VAS score was assessed at rest and during movement of lower legs. Postoperative pain scores, morphine consumption, and side effects were recorded until $48 \mathrm{hrs}$ after surgery. Assessments were performed preoperatively and at $0.25,0.5,1,4,8,16,24,36$, and $48 \mathrm{hrs}$ postoperatively (abbreviated to H0, H0.25, H0.5, H1, H4, H8, H16, H24, $\mathrm{H} 36$, and $\mathrm{H} 48$ ).

We used SPSS software (version 20.0, IBM, USA) to perform statistical analysis. Data were analyzed and results expressed by standard methods (mean \pm standard deviation). Comparative data between two groups were analyzed by Student's $t$-test (to compare mean differences in patient demographics, VAS, morphine consumption, sedation score) and Chi-square (to evaluate the difference in nonunion rates). $p$-value $<0.05$ was considered as significant.

The study was approved by the Ethics Committee of 103 Military Hospital. The study was in line with the
Declaration of Helsinki. Written informed consent has been provided to all participants after a thorough explanation of the purpose of this study.

\section{Results}

\section{Patient characteristics}

Table 1 shows the characteristics of the 60 patients completing the study. There were no differences in demographic characteristics, surgical duration, extubation time, or first analgesic requirement time.

\section{Morphine consumption}

Table 2 shows the average morphine consumption at each of the postoperative time, beginning with the initial morphine titration prior to initiation of PCA.

Total 48-hr cumulative morphine consumption was different between the two groups.

\section{VAS scores}

VAS score at rest was shown in Table 3 and Figure 2. At rest, the preemptive analgesia group had statistically significantly lower VAS at time points (H4, H8, H16, H24, H36, H48) than the control group.

VAS score at lower legs movement was shown in Table 4 and Figure 3. With movement, the preemptive analgesia group had statistically significantly lower VAS at time points (H0.5, H1, H4, H8, H16, H24, H36, H48) than the control group.

\section{Side effects}

Hemodynamics, respiratory rate, and $\mathrm{SpO}_{2}$ did not differ among the two treatment groups during the postoperative period (Table 5).

The level of sedation during the postoperative period was only statistically significant at H8 (Table 6).

Table I Patients demographic and clinical data

\begin{tabular}{|l|l|l|l|}
\hline & Preemptive analgesia group $(\mathbf{n}=30)$ & Control group (n=30) & $P$-value \\
\hline Age (years) & $44.93 \pm 10.26$ & $48.23 \pm I 1.88$ & 0.254 \\
Gender (male/female) & $3 / 2$ & $2 / 3$ & $158.33 \pm 7.15$ \\
Height (cm) & $161.30 \pm 6.74$ & $54.87 \pm 6.51$ & 0.103 \\
Weight (kg) & $56.67 \pm 5.76$ & $128.17 \pm 21.52$ & 0.261 \\
Duration of surgery (mins) & $128.33 \pm 20.52$ & $16.77 \pm 2.93$ & 0.976 \\
Extubation time (minutes after completion of surgery) & $16.70 \pm 2.40$ & $27.73 \pm 8.40$ & 0.919 \\
First analgesic requirement time (minutes after extubation) & $25.67 \pm 8.73$ & 0.355 \\
\hline
\end{tabular}

Notes: Results: mean \pm SD; analysis by Student's $t$-test. 
Table 2 Postoperative morphine consumption

\begin{tabular}{|l|l|l|l|}
\hline & $\begin{array}{l}\text { Preemptive analge- } \\
\text { sia group }(\mathbf{n}=\mathbf{3 0})\end{array}$ & $\begin{array}{l}\text { Control } \\
\text { group }(\mathbf{n}=\mathbf{3 0})\end{array}$ & P-value \\
\hline $\begin{array}{l}\text { Morphine } \\
\text { titration (mg) }\end{array}$ & $3.07 \pm 1.14$ & $4.50 \pm 1.50$ & $0.000 I^{*}$ \\
First 24 hrs & $24.43 \pm 4.94$ & $29.03 \pm 4.38$ & $0.0003^{*}$ \\
Next 24 hrs & $20.77 \pm 4.56$ & $23.83 \pm 4.739$ & $0.0134^{*}$ \\
$48 \mathrm{hrs}$ & $44.20 \pm 10.21$ & $52.23 \pm 9.57$ & $0.0026^{*}$ \\
\hline
\end{tabular}

Notes: Results: mean $\pm \mathrm{SD}$; ${ }^{*} p<0.05$ analysis by Student's $t$-test.

Table 3 VAS score at rest

\begin{tabular}{|l|l|l|l|}
\hline $\begin{array}{l}\text { Time } \\
\text { points }\end{array}$ & $\begin{array}{l}\text { Preemptive analgesia } \\
\text { group }(\mathbf{n = 3 0 )}\end{array}$ & $\begin{array}{l}\text { Control } \\
\text { group }(\mathbf{n = 3 0 )}\end{array}$ & P-value \\
\hline H0 & $5.43 \pm 0.68$ & $5.67 \pm 0.6 \mathrm{I}$ & 0.155 \\
H0.25 & $3.17 \pm 0.53$ & $3.27 \pm 0.64$ & 0.512 \\
H0.5 & $2.87 \pm 0.63$ & $2.90 \pm 0.76$ & 0.868 \\
HI & $2.67 \pm 0.48$ & $2.80 \pm 0.55$ & 0.333 \\
H4 & $5.23 \pm 0.77$ & $5.70 \pm 0.47$ & $0.006^{*}$ \\
H8 & $5.33 \pm 0.55$ & $6.00 \pm 0.95$ & $0.00 I^{*}$ \\
H16 & $4.87 \pm 0.73$ & $5.53 \pm 0.86$ & $0.002^{*}$ \\
H24 & $4.63 \pm 0.62$ & $5.43 \pm 0.89$ & $0.0002^{*}$ \\
H36 & $4.27 \pm 0.69$ & $4.77 \pm 1.10$ & $0.039^{*}$ \\
H48 & $4.33 \pm 0.96$ & $4.90 \pm 0.86$ & $0.018^{*}$ \\
\hline
\end{tabular}

Notes: Results: mean $\pm \mathrm{SD}$; ${ }^{*} p<0.05$ analysis by Student's $t$-test.

The incidence of nausea/vomiting in the preemptive group was not statistically different than the control group (1 vs 1 ).

\section{Discussion}

This study revealed that the combination of pregabalin and celecoxib is effective adjuncts to pain management after lumbar spine fusion surgery. This combination produced a significant reduction in pain scores at rest and with legs movement, and reduced morphine consumption during the first 48 postoperative hours.

Severe pain after spine surgery occurrs in $20-40 \%$ and last 3-4 days, increasing the risk of opioid-related respiratory depression, impairing neurological function. Delayed ambulation increases the risk of venous thrombosis. Inadequate postoperative pain management is not only associated with a greater incidence of complications as well as a lengthened hospital stay, but also increases the risk that persistent chronic pain will develop. Thus, it is of great concern for patients, surgeons, and anesthesiologists, and really benefits from a multidisciplinary approach. ${ }^{4,8,9}$ Many preoperative, intraoperative, and postoperative analgesia regimens have been proposed in order to achieve adequate pain management after spine surgery. In 2016, the American Pain Society made the recommendation that multimodal therapies be initiated in the preoperative period. ${ }^{10}$

There is a lack of evidence regarding optimal postoperative pain management after neurosurgery. ${ }^{11}$ Effective multimodal methods for spine surgery may

The preemptive analgesia group (blue line) had statistically significant lower VAS at time point $(\mathrm{H} 4, \mathrm{H} 8, \mathrm{H} 16, \mathrm{H} 24, \mathrm{H} 36, \mathrm{H} 48)$ than the control group (red line).

$P$ values are shown in Table 3 .

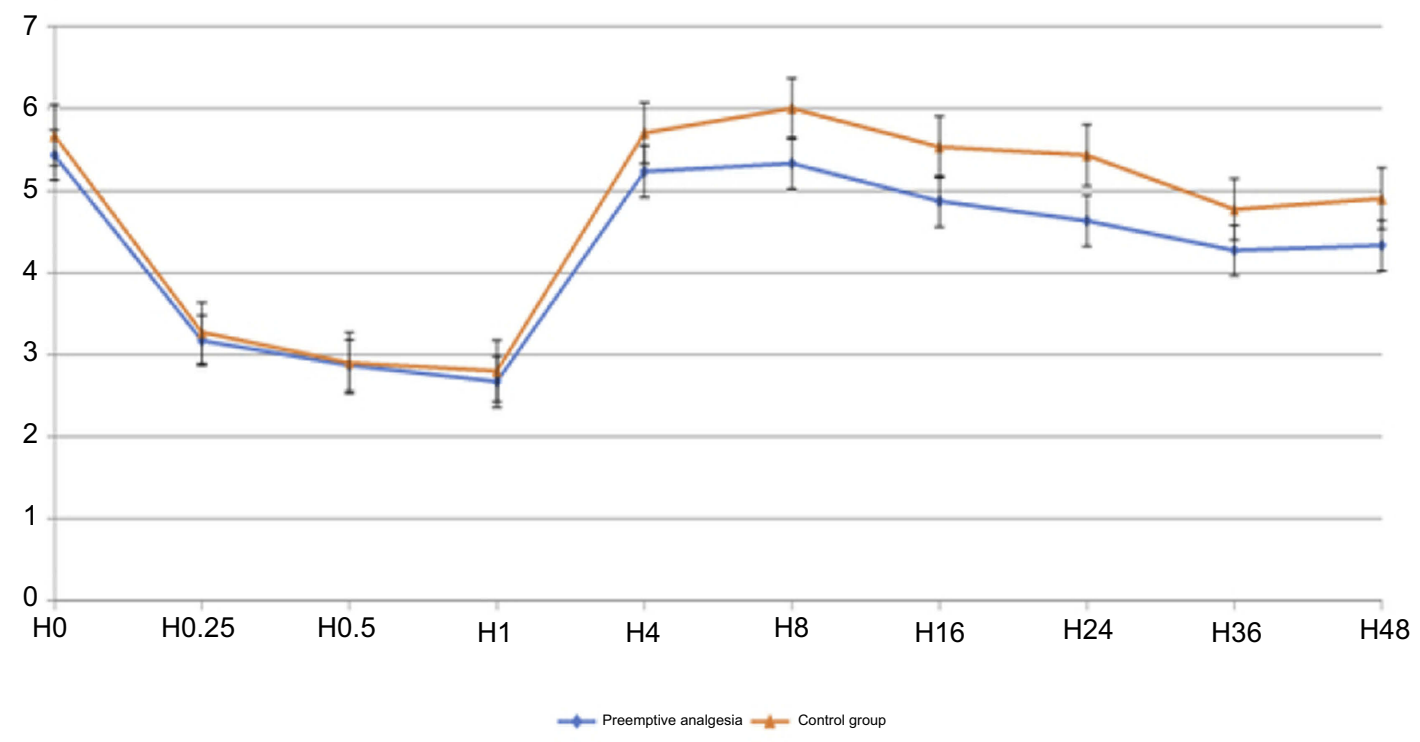

Figure 2 VAS score at rest. 
Table 4 VAS score during lower legs movement

\begin{tabular}{|l|l|l|l|}
\hline Group & $\begin{array}{l}\text { Preemptive analgesia } \\
\text { group }(\mathbf{n = 3 0})\end{array}$ & $\begin{array}{l}\text { Control } \\
\text { group }(\mathbf{n}=\mathbf{3 0})\end{array}$ & P-value \\
\hline $\mathrm{H} 0$ & $6.12 \pm 0.53$ & $6.21 \pm 0.63$ & $0.55 \mathrm{I}$ \\
$\mathrm{H} 0.25$ & $4.33 \pm 0.54$ & $4.64 \pm 0.66$ & $0.05 \mathrm{I}$ \\
$\mathrm{H} 0.5$ & $4.22 \pm 0.58$ & $5.57 \pm 0.57$ & $<0.000 I^{*}$ \\
$\mathrm{HI}$ & $4.17 \pm 0.45$ & $5.46 \pm 0.52$ & $<0.000 I^{*}$ \\
$\mathrm{H} 4$ & $4.26 \pm 0.7 \mathrm{I}$ & $5.72 \pm 0.64$ & $<0.000 I^{*}$ \\
$\mathrm{H} 8$ & $3.93 \pm 0.62$ & $5.67 \pm 0.53$ & $<0.000 I^{*}$ \\
$\mathrm{H} 16$ & $3.86 \pm 0.83$ & $5.54 \pm 0.72$ & $<0.000 I^{*}$ \\
$\mathrm{H} 24$ & $4.04 \pm 0.67$ & $5.42 \pm 0.66$ & $<0.000 I^{*}$ \\
$\mathrm{H} 36$ & $4.29 \pm 0.68$ & $4.7 I \pm 0.67$ & $0.019 *$ \\
$\mathrm{H} 48$ & $4.32 \pm 0.82$ & $4.94 \pm 0.84$ & $0.005^{*}$ \\
\hline
\end{tabular}

Notes: Results: mean \pm SD; ${ }^{*} p<0.05$ analysis by Student's $t$-test.

include the use of preemptive analgesia with non-steroidal anti-inflammatory drugs (NSAIDs), gabapentinoids (gabapentin and pregabalin), acetaminophen, and local anesthesia. ${ }^{12}$ Preemptive analgesia may improve patient satisfaction and quality of life by reducing postoperative pain narcotic consumption. ${ }^{6,7,13}$ Preemptive analgesia is a term that refers to treatment that starts before surgery, and is intended to prevent central sensitization caused by surgical incisional injury and other inflammatory responses to surgery. ${ }^{14}$ It has previously been found to be safe and effective after lumbar fusion surgery. ${ }^{15}$ In addition to the oral medications used in our study, a single caudal epidural injection or parenterally administered medications may also be effective. ${ }^{16}$

Preoperative use of gabapentinoids (pregabalin, gabapentin) showed a reduction in postoperative pain and total morphine consumption following spine surgery. ${ }^{17}$ After spine surgery, postoperative pain management with pregabalin was considered equivalent to gabapentin. Khurana, G. et al, showed that preoperative pregabalin administration is associated with less pain intensity and improved functional outcomes 3 months after lumbar discectomy, compared to gabapentin and placebo. ${ }^{18}$ In this study, we used $150 \mathrm{mg}$ pregabalin $2 \mathrm{hrs}$ before surgery. It is similar to some recent studies. ${ }^{19,20}$ In addition to these desirable effects, preoperative pregabalin also reduces intraoperative anesthetic agent requirements in patients who received general anesthesia by a total intravenous anesthesia technique. A reduction in pain at rest and during movement, and persistent neuropathic pain are additional benefits. ${ }^{21}$ For patients receiving general anesthesia, its use also decreases fentanyl consumption. Furthermore, it improves the quality of life up to 3 months after surgery. ${ }^{22}$

A prospective randomized double-blind controlled study of single preoperative oral dose $(120 \mathrm{mg})$ of Etoricoxib showed that reducing significantly post operative pain at rest and movement and improving sleep without any side effects in patient who had single-level discectomy. ${ }^{23} \mathrm{~A}$

The preemptive analgesia group (blue line) had statistically significant lower VAS at time point ( $\mathrm{H} 0.5, \mathrm{H} 1, \mathrm{H} 4, \mathrm{H} 8, \mathrm{H} 16, \mathrm{H} 24, \mathrm{H} 36, \mathrm{H} 48$ ) than the control group (red line).

$P$ values are shown in Table 4.

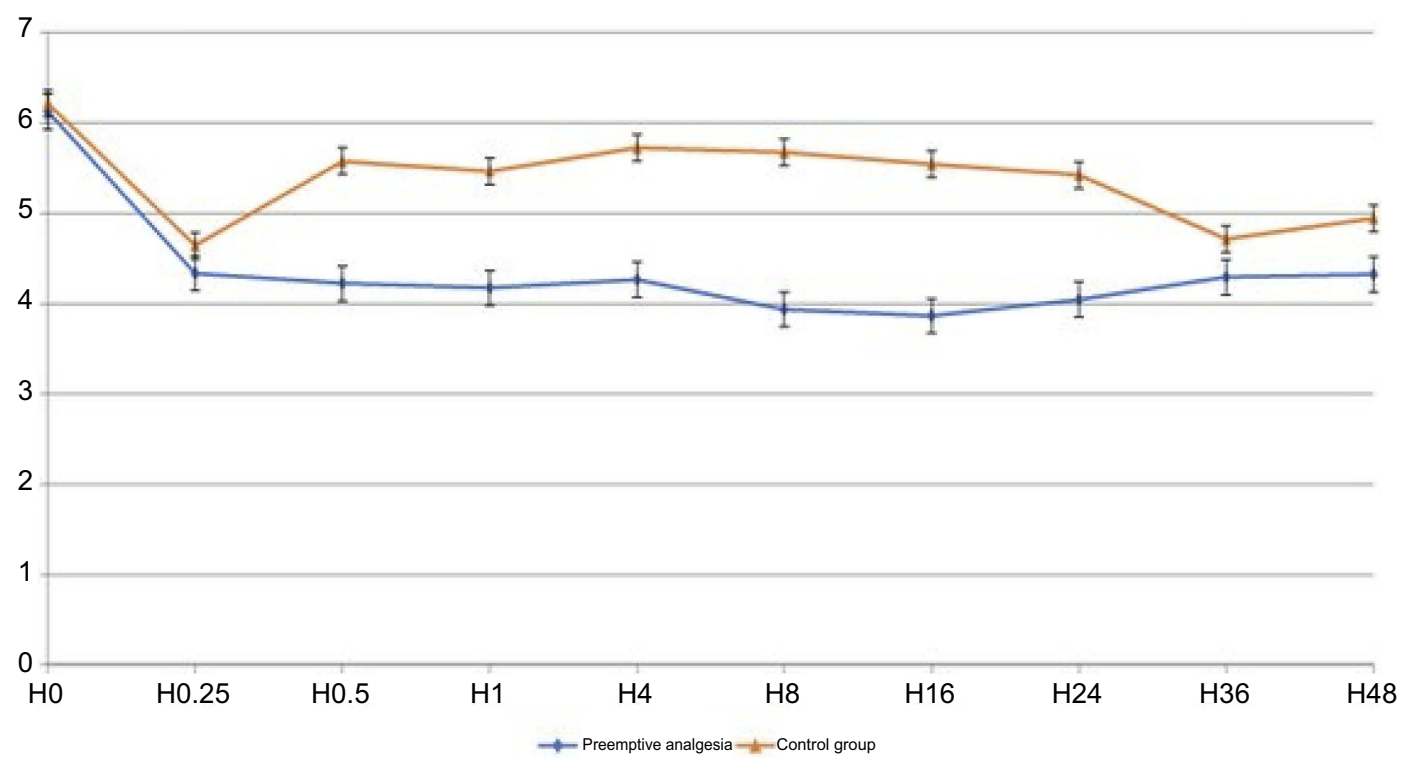

Figure 3 VAS score during lower legs movement. 
Table 5 Postoperative heart rate, mean arterial blood pressure and respiratory rate

\begin{tabular}{|c|c|c|}
\hline $\begin{array}{l}\text { Time after } \\
\text { surgery }\end{array}$ & $\begin{array}{l}\text { Preemptive analgesia } \\
\text { group }(n=30)\end{array}$ & $\begin{array}{l}\text { Control group } \\
(n=30)\end{array}$ \\
\hline \multicolumn{3}{|l|}{ Preoperative } \\
\hline $\mathrm{HR}$ & $83.60 \pm 5.11$ & $83.87 \pm 5.07$ \\
\hline MAP & $85.17 \pm 4.95$ & $85.62 \pm 3.08$ \\
\hline $\mathrm{RR}$ & $18.93 \pm 0.90$ & $18.63 \pm 0.76$ \\
\hline $\mathrm{SpO}_{2}$ & $96.83 \pm 1.31$ & $97.33 \pm 1.18$ \\
\hline \multicolumn{3}{|l|}{$0.25 \mathrm{hr}$} \\
\hline$H R$ & $82.70 \pm 5.23$ & $83.10 \pm 5.62$ \\
\hline MAP & $84.70 \pm 5.47$ & $85.24 \pm 3.99$ \\
\hline R R & $17.93 \pm 0.74$ & $18.00 \pm 0.78$ \\
\hline $\mathrm{SpO}_{2}$ & $96.70 \pm 1.12$ & $97.37 \pm 1.21$ \\
\hline \multicolumn{3}{|l|}{$0.5 \mathrm{hr}$} \\
\hline$H R$ & $81.40 \pm 5.05$ & $82.70 \pm 5.65$ \\
\hline MAP & $84.60 \pm 6.07$ & $84.83 \pm 3.44$ \\
\hline $\mathrm{RR}$ & $17.83 \pm 1.20$ & $17.57 \pm 1.22$ \\
\hline $\mathrm{SpO}_{2}$ & $96.60 \pm 1.16$ & $96.63 \pm 0.99$ \\
\hline \multicolumn{3}{|l|}{$\mathrm{I} \mathrm{hr}$} \\
\hline $\mathrm{HR}$ & $81.20 \pm 5.94$ & $82.67 \pm 6.62$ \\
\hline MAP & $85.60 \pm 5.65$ & $85.86 \pm 3.49$ \\
\hline $\mathrm{RR}$ & $18.40 \pm 0.62$ & $18.17 \pm 0.83$ \\
\hline $\mathrm{SpO}_{2}$ & $96.70 \pm 1.34$ & $97.00 \pm 1.08$ \\
\hline \multicolumn{3}{|l|}{$4 \mathrm{hrs}$} \\
\hline HR & $81.73 \pm 6.29$ & $82.70 \pm 6.07$ \\
\hline MAP & $83.57 \pm 5.11$ & $84.69 \pm 4.67$ \\
\hline $\mathrm{RR}$ & $18.30 \pm 0.87$ & $18.43 \pm 0.85$ \\
\hline $\mathrm{SpO}_{2}$ & $96.77 \pm 1.04$ & $97.00 \pm 0.94$ \\
\hline \multicolumn{3}{|l|}{$8 \mathrm{hrs}$} \\
\hline $\mathrm{HR}$ & $81.83 \pm 6.24$ & $82.40 \pm 5.77$ \\
\hline MAP & $83.30 \pm 5.15$ & $84.72 \pm 5.09$ \\
\hline $\mathrm{RR}$ & $17.90 \pm 1.06$ & $18.20 \pm 0.99$ \\
\hline $\mathrm{SpO}_{2}$ & $96.70 \pm 1.08$ & $97.10 \pm 1.29$ \\
\hline \multicolumn{3}{|l|}{$16 \mathrm{hrs}$} \\
\hline HR & $81.93 \pm 5.71$ & $82.47 \pm 5.50$ \\
\hline MAP & $82.10 \pm 5.17$ & $83.55 \pm 5.65$ \\
\hline$R R$ & $18.70 \pm 0.70$ & $18.70 \pm 0.83$ \\
\hline $\mathrm{SpO}_{2}$ & $97.03 \pm 0.93$ & $97.07 \pm 1.05$ \\
\hline \multicolumn{3}{|l|}{$24 \mathrm{hrs}$} \\
\hline$H R$ & $82.07 \pm 5.68$ & $83.10 \pm 5.7 \mid$ \\
\hline MAP & $83.70 \pm 5.4 I$ & $85.3 I \pm 5.47$ \\
\hline $\mathrm{RR}$ & $|9.10 \pm 0.7|$ & $19.17 \pm 0.87$ \\
\hline $\mathrm{SpO}_{2}$ & $96.60 \pm 0.89$ & $96.53 \pm 0.68$ \\
\hline \multicolumn{3}{|l|}{$36 \mathrm{hrs}$} \\
\hline$H R$ & $82.17 \pm 5.90$ & $82.70 \pm 5.39$ \\
\hline MAP & $84.17 \pm 5.093$ & $85.45 \pm 5.22$ \\
\hline $\mathrm{RR}$ & $18.53 \pm 0.86$ & $18.63 \pm 0.85$ \\
\hline $\mathrm{SpO}_{2}$ & $96.70 \pm 1.02$ & $97.30 \pm 1.29$ \\
\hline
\end{tabular}

(Continued)
Table 5 (Continued).

\begin{tabular}{|l|l|l|}
\hline $\begin{array}{l}\text { Time after } \\
\text { surgery }\end{array}$ & $\begin{array}{l}\text { Preemptive analgesia } \\
\text { group }(\mathbf{n = 3 0})\end{array}$ & $\begin{array}{l}\text { Control group } \\
(\mathbf{n}=\mathbf{3 0})\end{array}$ \\
\hline $48 \mathrm{hrs}$ & & \\
$\mathrm{HR}$ & $81.87 \pm 5.86$ & $82.50 \pm 6.73$ \\
$\mathrm{MAP}$ & $84.43 \pm 6.06$ & $84.31 \pm 6.32$ \\
$\mathrm{RR}$ & $19.30 \pm 0.95$ & $18.93 \pm 0.98$ \\
$\mathrm{SpO}_{2}$ & $96.90 \pm 1.27$ & $96.67 \pm 1.29$ \\
\hline
\end{tabular}

Notes: Data are presented as mean $\pm \mathrm{SD}$. $\mathrm{SpO}_{2}$ (\%): There were no statistical differences between two groups.

Abbreviations: HR (bpm), heart rate; MAP $(\mathrm{mm} \mathrm{Hg})$, mean arterial blood pressure; RR (breaths/min), respiratory rate.

Table 6 Sedation score

\begin{tabular}{|l|l|l|l|}
\hline $\begin{array}{l}\text { Time } \\
\text { points }\end{array}$ & $\begin{array}{l}\text { Preemptive analgesia } \\
\text { group }(\mathbf{n}=\mathbf{3 0})\end{array}$ & $\begin{array}{l}\text { Control } \\
\text { group }(\mathbf{n = 3 0})\end{array}$ & P-value \\
\hline $\mathrm{H} 0.5$ & $0.73 \pm 0.58$ & $0.87 \pm 0.73$ & 0.414 \\
$\mathrm{HI}$ & $0.80 \pm 0.66$ & $0.80 \pm 0.66$ & 1.00 \\
$\mathrm{H} 4$ & $0.63 \pm 0.66$ & $0.77 \pm 0.67$ & 0.418 \\
$\mathrm{H} 8$ & $1.10 \pm 0.40$ & $1.47 \pm 0.77$ & $0.023 *$ \\
$\mathrm{H} 16$ & $0.97 \pm 0.71$ & $0.97 \pm 0.80$ & 1.00 \\
$\mathrm{H} 24$ & $0.93 \pm 0.64$ & $0.87 \pm 0.68$ & 0.726 \\
$\mathrm{H} 36$ & $0.83 \pm 0.64$ & $0.83 \pm 0.64$ & 1.00 \\
$\mathrm{H} 48$ & $0.57 \pm 0.56$ & $0.43 \pm 0.50$ & 0.311 \\
\hline
\end{tabular}

Notes: Results: mean $\pm \mathrm{SD} ;{ }^{*} p<0.05$ analysis by Student's $t$-test.

meta-analysis by Gupta et al, showed that NSAIDs do not increase the incidence of adverse effects in the acute period after surgery. ${ }^{24}$ This safety profile has also been demonstrated in spinal surgery. ${ }^{25}$ In the management of acute postoperative pain, COX-2 inhibitors may impart certain clinical advantages over other NSAIDs due to their reduced effects on platelets. ${ }^{26} \mathrm{~A}$ study in rabbits and meta-analyses in NSAIDs (ketorolac, diclofenac sodium, celecoxib, or rofecoxib) with normal-dose showed celecoxib was safe in the two weeks following spinal fusion. ${ }^{27,28}$ In addition, the analgesic effect of celecoxib was exhibited quickly and sustained. ${ }^{29}$ Although our results differ from those of Karst et al, ( $\mathrm{n}=34$ : Celecoxib has no effect on postoperative pain scores after lumbar microdiscectomy), ${ }^{30}$ we suspect the reason behind their finding of non-efficacy is related to their concomitant use of anti-inflammatory steroid and a smaller sample size. Recent studies also have shown loxoprofen sodium has superior and rapid effectiveness compared with celecoxib after spinal surgery. ${ }^{31}$ Further studies may be needed to detect and more precisely measure undesired side effects after spinal surgery.

The preoperative administration of the combination of pregabalin and celecoxib improved analgesia. Li, Z., et al, 
study also showed this combination during the perioperative period can reduce pain after surgery and the incidence of postoperative neuropathic pain. ${ }^{32}$ The addition of celecoxib has been shown to be more effective than the use of gabapentinoids alone. ${ }^{33}$ In our study, the pain score and morphine consumption of the preemptive analgesia group was significantly lower than the control group (Table 2). In the study of Fujita 2016 also found that administration of $150 \mathrm{mg}$ of pregabalin 2 hrs before spine surgery decreased postoperative pain intensity and morphine consumption. ${ }^{19}$ Another study using 150-300 mg orally perioperatively has been shown to reduce both pain and narcotic consumption and improve patient's satisfaction after spinal surgery. ${ }^{7}$

Many studies have demonstrated that multimodal therapy is superior to single agent methods for postoperative pain management. This is the result of action on different sites in the transmitting pain pathways. ${ }^{34,35}$ Pinar, H.U., et al, study showed that preemptive analgesia with ibuprofen and pregabalin safely decreased postoperative pain and total morphine consumption in spine surgery. ${ }^{36}$ Preemptive multimodal (celecoxib, pregabalin, extended-release oxycodone, and acetaminophen) analgesic regimen have been done with significantly lower VAS in the multimodal analgesia group at all time points within 7 postoperative days. ${ }^{15}$

\section{Limitations of study}

This study aimed to provide the uses of available drug in the clinical context in the Vietnamese population. There were no pharmacokinetics and pharmacodynamics evaluations about combination treatment effect.

\section{Conclusions}

Preoperative administration of pregabalin combined with celecoxib had a good preemptive analgesia effect and reduced intravenous morphine consumption after lumbar spine surgery. Side effects were mild and transient.

\section{Disclosure}

The authors have no funding and conflicts of interest to disclose in this work.

\section{References}

1. Apfelbaum JL, Chen C, Mehta SS, Gan TJ. Postoperative pain experience: results from a national survey suggest postoperative pain continues to be undermanaged. Anesth Analg. 2003;97(2):534-540, table of contents

2. Coronado RA, George SZ, Devin CJ, Wegener ST, Archer KR. Pain sensitivity and pain catastrophizing are associated with persistent pain and disability after lumbar spine surgery. Arch Phys Med Rehabil. 2015;96(10):1763-1770. doi:10.1016/j.apmr.2015.06.003
3. Bajwa SJS, Haldar R. Pain management following spinal surgeries: an appraisal of the available options. J Craniovertebr Junction Spine. 2015;6(3):105-110. doi:10.4103/0974-8237.161589

4. Puvanesarajah V, Liauw JA, Lo S-F, Lina IA, Witham TF, Gottschalk A. Analgesic therapy for major spine surgery. Neurosurg Rev. 2015;38(3):407-419. doi:10.1007/s10143-015-0605-7

5. Beverly A, Kaye AD, Ljungqvist O, Urman RD. Essential elements of multimodal analgesia in enhanced recovery after surgery (ERAS) guidelines. Anesthesiol Clin. 2017;35(2):e115-e143. doi:10.1016/j. anclin.2017.01.018

6. Lee BH, Park J-O, Suk K-S, et al. Pre-emptive and multi-modal perioperative pain management may improve quality of life in patients undergoing spinal surgery. Pain Physician. 2013;16(3): E217-E226.

7. Rivkin A, Rivkin MA. Perioperative nonopioid agents for pain control in spinal surgery. Am J Health Syst Pharm. 2014;71(21):18451857. doi:10.2146/ajhp130688

8. Ali Z, Prabhakar H. Pain following Spinal Surgery, in Complications in Neuroanesthesia. Elsevier Inc; 2016:283-294. doi:10.1016/C2015-000811-5

9. Ali Z, Singh S, Hassan N, Naqash I. Pain management. In: Essentials of Neuroanesthesia. Elsevier; 2017:835-851. doi:10.1016/B978-012-805299-0.00051-8

10. Chou R, Gordon DB, de Leon-Casasola OA, et al. Management of postoperative pain: a clinical practice guideline from the American pain society, the American society of regional anesthesia and pain medicine, and the American society of anesthesiologists' committee on regional anesthesia, executive committee, and administrative council. J Pain. 2016;17(2):131-157. doi:10.1016/j.jpain.2015.12.008

11. Grodofsky S. Chronic pain in neurosurgery. Anesthesiol Clin. 2016;34(3):479-495. doi:10.1016/j.anclin.2016.04.003

12. Kurd MF, Kreitz T, Schroeder G, Vaccaro AR. The role of multimodal analgesia in spine surgery. JAAOS. 2017;25(4):260-268. doi:10.5435/JAAOS-D-16-00049

13. Savitha KS, Dhanpal R, Kothari AN. The effect of multimodal analgesia on intraoperative morphine requirement in lumbar spine surgeries. Anesth Essays Res. 2017;11(2):397. doi:10.4103/02591162.194553

14. Kissin I. Preemptive analgesia. Anesthesiology. 2000;93(4):1138-1143.

15. Kim S-I, Ha K-Y, Oh I-S. Preemptive multimodal analgesia for postoperative pain management after lumbar fusion surgery: a randomized controlled trial. Eur Spine J. 2016;25(5):1614-1619. doi:10.1007/s00586-015-4216-3

16. Sekar C, Rajasekaran S, Kannan R, Reddy S, Shetty TAP, Pithwa YK. Preemptive analgesia for postoperative pain relief in lumbosacral spine surgeries: a randomized controlled trial. Spine J. 2004;4 (3):261-264. doi:10.1016/j.spinee.2003.11.009

17. Liu B, Liu R, Wang L. A meta-analysis of the preoperative use of gabapentinoids for the treatment of acute postoperative pain following spinal surgery. Medicine (United States). 2017;96(37):1-11.

18. Khurana G, Jindal P, Sharma JP, Bansal KK. Postoperative pain and long-term functional outcome after administration of gabapentin and pregabalin in patients undergoing spinal surgery. Spine. 2014;39(6): E363-E368. doi:10.1097/BRS.0000000000000185

19. Fujita N, Tobe M, Tsukamoto N, Saito S, Obata H. A randomized placebo-controlled study of preoperative pregabalin for postoperative analgesia in patients with spinal surgery. J Clin Anesth. 2016;31:149153. doi: $10.1016 /$ j.jclinane.2016.01.010

20. Jiang HL, Huang S, Song J, Wang X, Cao ZS. Preoperative use of pregabalin for acute pain in spine surgery. Medicine (United States). 2017;96(11):1-9.

21. Canos A, Cort L, Fernández Y, et al. Preventive analgesia with pregabalin in neuropathic pain from "failed back surgery syndrome": assessment of sleep quality and disability. Pain Med. 2016;17(2):344-352. doi:10.1111/ pme. 12895 
22. Gianesello L, Pavoni V, Barboni E, Galeotti I, Nella A. Perioperative pregabalin for postoperative pain control and quality of life after major spinal surgery. J Neurosurg Anesthesiol. 2012;24(2):121-126. doi:10.1097/ANA.0b013e31823a885b

23. Srivastava S, Gupta D, Naz A, Rizvi MM, Singh PK. Effects of preoperative single dose Etoricoxib on postoperative pain and sleep after lumbar diskectomy: prospective randomized double blind controlled study. Middle East J Anaesthesiol. 2012;21 (5):725-730.

24. Gupta A, Bah M. NSAIDs in the treatment of postoperative pain. Curr Pain Headache Rep. 2016;20(11). doi:10.1007/s11916-016-0591-7

25. Zhang Z, Xu H, Zhang Y, et al. Nonsteroidal anti-inflammatory drugs for postoperative pain control after lumbar spine surgery: a metaanalysis of randomized controlled trials. J Clin Anesth. 2017;43:8489. doi:10.1016/j.jclinane.2017.08.030

26. Sinatra R. Role of COX-2 inhibitors in the evolution of acute pain management. J Pain Symptom Manage. 2002;24(1):S18-S27.

27. Li Q, Zhang Z, Cai Z. High-dose ketorolac affects adult spinal fusion: a meta-analysis of the effect of perioperative nonsteroidal antiinflammatory drugs on spinal fusion. Spine (Phila Pa 1976). 2011;36(7):E461-E468. doi:10.1097/BRS.0b013e3181dfd163

28. Long J, Lewis S, Kuklo T, Zhu Y, Riew KD. The effect of cyclooxygenase-2 inhibitors on spinal fusion. J Bone Joint Surg Am. 2002;84 (10):1763-1768. doi:10.2106/00004623-200210000-00004

29. Aoki T, Ota Y, Mori Y, Otsuru M, Ota M, Kaneko A. Analgesic efficacy of celecoxib in patients after oral surgery: special reference to time to onset of analgesia and duration of analgesic effect. Oral Maxillofac Surg. 2016;20 (3):265-271. doi:10.1007/s10006-016-0565-2
30. Karst M, Kegel T, Lukas A, Lüdemann W, Hussein S, Piepenbrock S. Effect of celecoxib and dexamethasone on postoperative pain after lumbar disc surgery. Neurosurgery. 2003;53(2):331-337. doi:10.1227/01.neu.0000073530.81765.6b

31. Sekiguchi H, Inoue G, Nakazawa T, et al. Loxoprofen sodium and celecoxib for postoperative pain in patients after spinal surgery: a randomized comparative study. J Orthop Sci. 2015;20(4):617-623. doi:10.1007/s00776-015-0726-4

32. Li Z, Zeng J, Nie H, Jiang H, Xie T, Song Y. Effectiveness of combined Pregabalin and Celecoxib for treatment of neuropathic pain after percutaneous endoscopic lumbar discectomy. Zhongguo Xiu Fu Chong Jian Wai Ke Za Zhi. 2017;31(2):215-221. doi:10.7507/1002-1892.201609084

33. Vasigh A, Jaafarpour M, Khajavikhan J, Khani A. The effect of gabapentin plus celecoxib on pain and associated complications after laminectomy. JCDR. 2016;10(3):UC04.

34. Singh K, Bohl DD, Ahn J, et al. Multimodal analgesia versus intravenous patient-controlled analgesia for minimally invasive transforaminal lumbar interbody fusion procedures. Spine (Phila Pa 1976). 2017;42(15):1145-1150. doi:10.1097/BRS.0000000000001992

35. Cillo JE Jr, Dattilo DJ. Pre-emptive analgesia with pregabalin and celecoxib decreases postsurgical pain following maxillomandibular advancement surgery: a randomized controlled clinical trial. J Oral Maxillofac Surg. 2014;72(10):1909-1914. doi:10.1016/j.joms.2014.05.014

36. Pinar HU, Karaca Ö, Karakoç F, Doğan R. Effects of addition of preoperative intravenous ibuprofen to pregabalin on postoperative pain in posterior lumbar interbody fusion surgery. Pain Res Manag. 2017;2017. doi:10.1155/2017/8123812
Drug Design, Development and Therapy

\section{Publish your work in this journal}

Drug Design, Development and Therapy is an international, peerreviewed open-access journal that spans the spectrum of drug design and development through to clinical applications. Clinical outcomes, patient safety, and programs for the development and effective, safe, and sustained use of medicines are a feature of the journal, which has also been accepted for indexing on PubMed Central. The manuscript management system is completely online and includes a very quick and fair peer-review system, which is all easy to use. Visit http://www. dovepress.com/testimonials.php to read real quotes from published authors. 